\title{
INTERNALISASI NILAI-NILAI PENDIDIKAN AGAMA ISLAM DALAM PEMBELAJARAN BERBASIS SENTRA DI TAMAN KANAK-KANAK ISLAM TERPADU AL-HIJRAH BINTUJU KABUPATEN TAPANULI SELATAN
}

\author{
Maisaroh \\ Institut Agama Islam Negeri Padangsidimpuan \\ Jln. T. Rizal Nurdin Km. 4,5 Sihitang Padangsidimpuan 22733 \\ maisarohmpd@gmail.com
}

\begin{abstract}
Abstrak
Penelitian ini bertujuan untuk mendeskripsikan internalisasi nilai-nilai Pendidikan Agama Islam dalam pembelajaran berbasis sentra. Penelitian ini digolongkan kepada penelitian kualitatif, dengan instrumen pengumpulan datanya observasi, wawancara dan studi dokumen. Analisis data yang digunakan adalah analisis kualitatif deskriptif. Hasil penelitian menunjukkan bahwa: 1. Nilai-nilai Pendidikan Agama Islam yang diinternalisasikan dalam sentra al-Islam ada tiga yaitu: a. Nilai akidah b. Nilai ibadah. c.Nilai akhlak. Metode internalisasinya: Ceramah, tanya jawab, pembiasaan, keteladanan, nasehat, perhatian dan pengawasan dan kisah. 2. Nilai-nilai Pendidikan Agama Islam yang diinternalisasikan dalam sentra bahasa ada tiga, yaitu: a. Nilai akidah. b. Nilai ibadah. c. Nilai akhlak. 3. Nilai yang diinternalisasikan dalam sentra kognitif, ada tiga, yaitu: a. nilai akidah. b. nilai ibadah. c. Nilai akhlak. 4. Nilai yang diinternalisasikan dalam sentra sains adalah nilai akidah dan akhlak.
\end{abstract}

\section{Abstract}

This study aims to describe internalizing values of Islamic Religious Education in learning based centre. This research is classified into qualitative research. Data collection instruments used were observation, interviews and document study. Data analysis used is descriptive qualitative analysis. From the research carried out, the results were obtained, namely: 1. The values of Islamic Religious Education internalized in the center of al-Islam are three, namely: a. Faith value b. Value of worship. c. Moral values. Internalization method: Lecture, question and answer, habituation, exemplary, advice, attention and supervision and story. 2. The values of Islamic Religious Education that are internalized in a language center are three, namely: a. Faith value. b. Value of worship. c. Moral values. 3. There are three values that are internalized in the cognitive center, namely: a. value of faith. b. value of worship. c. Moral values. 4. The values internalized in the center of science are the values of aqeed and morals.

Kata Kunci: Internalisasi, Pendidikan Agama Islam, Pembelajaran Berbasis Sentra 


\section{Pendahuluan}

Pendidikan anak usia dini (PAUD) pada hakikatnya adalah pendidikan yang diselenggarakan dengan tujuan untuk memfasilitasi pertumbuhan dan perkembangan anak secara menyeluruh dan menekankan pada pengembangan seluruh aspek kepribadian anak untuk membentuk karakter anak. ${ }^{1}$ Perhatian terhadap pendidikan anak usia dini merupakan wujud komitmen pemerintah Indonesia sebagai anggota Persatuan Bangsa-bangsa (PBB) terhadap hasil pertemuan dunia Education for All yang diselenggarakan di Dakar tahun 2000. ${ }^{2}$

Dalam perkembangannya, masyarakat telah menunjukkan kepedulian terhadap masalah pendidikan, pengasuhan dan perlindungan anak usia dini mulai usia 0 hingga 6 tahun dengan berbagai layanan sesuai dengan kondisi dan kemampuan yang ada. Pendidikan anak usia dini (PAUD) jalur pendidikan formal berbentuk Taman Kanak-kanak (TK) atau Raudatul Atfal (RA) yang menggunakan program usia 4 hingga 6 tahun. Adapun penyelenggaraan pendidikan anak usia dini (PAUD) jalur nonformal berbentuk Taman Penitipan Anak (TPA) dan bentuk lain yang sederajat, yang menggunakan program untuk anak usia $0-<2$ tahun, $2-<4$ tahun, $4-<6$ tahun. ${ }^{3}$

Salah satu materi pendidikan yang secara serius harus diberikan untuk anak Taman Kanak-kanak (TK) adalah materi Pendidikan Agama Islam. Hal ini dimaksudkan supaya anak memiliki pemahaman dasar, keyakinan, dan kecintaan mereka terhadap agama (Islam) yang mereka anut serta sebagai bekal anak dalam mengamalkan ajaran-ajaran agama (Islam). Oleh karena itu, perlu adanya proses internalisasi nilai-nilai Pendidikan Agama Islam (PAI) di lembaga pendidikan Taman Kanak-Kanak dan hal ini yang dilakukan di Taman Kanak-kanak (TK) Islam Terpadu Al-Hijrah Bintuju Kabupaten Tapanuli Selatan.

Hal ini sejalan dengan pendapat Miftahul Achyar bahwa usia 0 sampai 6 tahun merupakan masa pertumbuhan dan perkembangan yang sangat menentukan bagi anak di masa depannya atau disebut juga masa keemasaan. ${ }^{4}$ Salah satu aspek yang perlu diperhatikan pada masa ini adalah aspek perkembangan agama dan moral anak. Menurut Muhammad Najib

${ }^{1}$ Miftahul Achyar Kertamuda, Golden Age (Jakarta: Gramedia, 2015), hlm. 10.

${ }^{2}$ Miftahul Achyar Kertamuda, Golden Age, hlm. 10.

${ }^{3}$ Mukhtar Latif, dkk, Pendidikan Anak Usia Dini (Jakarta: Kencana, 2013), hlm. 6.

${ }^{4}$ Miftahul Achyar Kertamuda, Golden Age..., hlm. 5. 


\section{Maisaroh}

perkembangan agama dan moral pada anak usia dini terkait dengan kecerdasan spritual (spritual quotient/SQ) anak.

\section{Konsep Pendidikan Agama Islam}

Banyak orang yang merancukan pengertian istilah "Pendidikan Agama Islam" dan "pendidikan Islam". Kedua istilah ini dianggap sama, sehingga ketika seseorang berbicara tentang pendidikan Islam ternyata isinya terbatas pada Pendidikan Agama Islam, atau sebaliknya ketika seseorang berbicara tentang Pendidikan Agama Islam justru yang dibahas di dalamnya adalah tentang pendidikan Islam. Padahal kedua istilah itu memiliki subtansi yang berbeda. $^{5}$

Menurut Muhaimin, bahwa pendidikan Islam merupakan salah satu bagian dari pendidikan Islam, yang mana pendidikan Islam merupakan nama sistem, yaitu sistem pendidikan yang Islami, yang memiliki komponenkomponen yang secara keseluruhan mendukung terwujudnya sosok muslim yang diidealkan. Pendidikan Islam ialah pendidikan yang teori-teorinya disusun berdasarkan alquran dan hadis. ${ }^{6}$

Pendidikan Agama Islam adalah usaha sadar untuk menyiapkan siswa dalam menyakini, memahami, menghayati dan mengamalkan agama Islam melalui kegiatan bimbingan, pengajaran atau latihan dengan memperhatikan tuntutan untuk menghormati agama lain dalam hubungan kerukunan antar umat beragama dalam masyarakat untuk mewujudkan persatuan nasional. ${ }^{7}$ Usaha tersebut juga melibatkan semua aktvitas pembelajaran sehingga ada saling dukung mendukung untuk mencapai tujuan bersama. Keterlibatan guru dan siswa adalah modal dasar usaha pembelajaran dapat dilakukan secara sistematis dan menyeluruh sebab kedua objek pendidikan itulah yang langsung merasakan keberhasilan pendidikan secara konkrit. ${ }^{8}$

\section{Ruang Lingkup Pendidikan Agama Islam}

1. Alquran-Hadis

${ }^{5}$ Muhaimin, Pengembangan Kurikulum Pendidikan Agama Islam (Jakarta: PT. RajaGrafindo Persada, 2010), hlm. 6.

${ }^{6}$ Muhaimin, Pengembangan Kurikulum ..., hlm. 6.

${ }^{7}$ Muhaimin, Paradigma Pendidikan Islam (Bandung: Remaja Rosdakarya, 2002), hlm. 75-76.

${ }^{8}$ Asfiati, Manajemen Pembelajaran Pendidikan Agama Islam (Bandung: Citapustaka Media, 2014), hlm. 32-33. 
Mata pelajaran alquran-hadis merupakan unsur mata pelajaran Pendidikan Agama Islam (PAI) yang memberikan pendidikan kepada peserta didik untuk memahami dan mencintai alquran dan hadis sebagai sumber ajaran Islam dan mengamalkan isi kandungannya dalam kehidupan seharihari. ${ }^{9}$

2. Akidah-akhlak

Yang dimaksud dengan akidah secara etimologi adalah ikatan, sangkutan. Disebut demikian, karena ia mengikat dan menjadi sangkutan segala sesuatu. Dalam pengertian teknis artinya adalah iman atau keyakinan. Akidah Islam karena itu, ditautkan dengan rukun iman yang menjadi asas seluruh ajaran Islam. kedudukannya sangat sentral dan fundamental, karena menjadi asas dan sekaligus sangkutan atau gantungan segala sesuatu dalam Islam juga menjadi titik tolak kegiatan seorang muslim. ${ }^{10}$

Mata pelajaran akidah-akhlak bertujuan untuk menumbuhkan dan meningkatkan keimanan peserta didik yang diwujudkan dalam akhlak yang terpuji melalui pemberian dan pemupukan pengetahuan, penghayatan serta pengamalan peserta didik tentang akidah dan akhlak Islam, sehingga menjadi manusia muslim yang terus berkembang dan meningkat kualitas keimanan dan ketakwaannya kepada Allah Swt, serta berakhlak mulia dalam kehidupan pribadi, bermasyarakat, berbangsa dan bernegara. ${ }^{11}$

3. Fikih

Dilihat dari segi ilmu pengetahuan yang berkembang dalam kalangan ulama Islam, fikih adalah ilmu pengetahuan yang membicarakan/membahas/memuat hukum-hukum Islam yang bersumber pada alquran, sunnah dan dalili-dalil syar'i yang lain, setelah diformulasikan oleh para ulama dengan mempergunakan kaidah-kaidah ushul fikih. ${ }^{12}$ Mata pelajaran fikih dimaksudkan sebagai bagian dari Pendidikan Agama Islam (PAI) yang diarahkan untuk menyiapkan peserta didik untuk mengenal, memahami, menghayati dan mengamalkan hukum Islam yang kemudian

${ }^{9}$ Ali Mudlofir, Aplikasi Pengembangan Kurikulum Tingkat Satuan Pendidikan dan Bahan Ajar Dalam Pendidikan Agama Islam (Jakarta: Rajawali Pres, 2012), hlm. 46-47.

${ }^{10}$ Mohammad Daud Ali, Pendidikan Agama Islam (Jakarta: RajaGrafindo Persada, 2011), hlm. 199.

${ }^{11}$ Ali Mudlofir, Aplikasi Pengembangan Kurikulum..., hlm. 50.

${ }^{12 Z a k i a h ~ D a r a d j a t, ~ M e t o d i k ~ K h u s u s ~ P e n g a j a r a n ~ A g a m a ~ I s l a m ~(J a k a r t a: ~ B u m i ~}$ Aksara, 2014), hlm. 78. 


\section{Maisaroh}

menjadi dasar pandangan hidupnya melalui kegiatan bimbingan, pengajaran, latihan, penggunaan pengalaman, pembiasaan dan keteladanan. ${ }^{13}$

4. Sejarah Kebudayaan Islam (SKI)

Sejarah kebudayaan Islam (SKI) merupakan salah satu bagian dari Pendidikan Agama Islam. Sejarah kebudayaan Islam yaitu sejarah yang berhubungan dengan pertumbuhan dan perkembangan umat Islam, dilihat dari segi yang umum, sejarah ini merupakan salah satu aspek dari agama Islam.

Mata pelajaran sejarah kebudayaan Islam (SKI) diarahkan untuk menyiapkan peserta didik untuk mengenal, memahami, menghayati sejarah kebudayaan Islam yang kemudian menjadi dasar pandangan hidupnya (way of life) melalui kegiatan bimbingan, pengajaran, latihan, penggunaan pengalaman, pembiasaan dan keteladanan. ${ }^{14}$

\section{Nilai-Nilai Pendidikan Agama Islam (PAI)}

Nilai-nilai dalam Islam mengandung dua kategori arti. Dilihat dari sudut normatif, yaitu pertimbangan tentang baik-buruk, benar dan salah, haq dan bathil, diridhai dan dikutuk oleh Allah SWT. Sedangkan bila dilihat dari sudut operatif, nilai itu mengandung lima pengertian katagorial yang menjadi prinsip perilaku manusia, yaitu:

1) Wajib, apa-apa yang mutlak diperintahkan, nilainya baik.

2) Sunnah, hal-hal yang dianjurkan untuk dikerjakan, nilainya setengah baik.

3) Mubah, apa-apa yang disuruh tidak, dilarang pun tidak, nilainya netral.

4) Makruh, hal-hal yang dianjurkan untuk dijauhi, nilainya setengah buruk.

5) Haram, apa-apa yang mutlak dilarang, nilainya buruk. ${ }^{15}$

Jika suatu nilai dikaitkan dengan pendidikan, maka misi agama Islam adalah memberikan rahmat kepada makhluk sekalian alam, khususnya pada makhluk yang diberi nama manusia agar mereka memperoleh kebahagian hidup di dunia maupun akhirat. Proses kependidikan manusiawi itu bertumpu kepada kemampuan rohaniah dan jasmaniah masing-masing individu manusia itu sendiri, secara bertahap dan berkesinambungan. ${ }^{16}$

${ }^{13}$ Ali Mudlofir, Aplikasi Pengembangan Kurikulum..., hlm. 53.

${ }^{14}$ Ali Mudlofir, Aplikasi Pengembangan Kurikulum..., hlm. 54.

${ }^{15}$ Khoiron Rosyadi, Pendidikan Profetik ...., hlm. 124.

${ }^{16}$ Eneng Muslihah, IImu Pendidikan Islam (Jakarta: Diadit Media, 2011), hlm. 219. 
Menurut Zakiah Daradjat Pendidikan Agama Islam dilihat dari sudut pengajarannya memiliki empat nilai, yaitu:

1. Nilai material

Yang dimaksud dengan nilai material adalah sejumlah pengetahuan agama Islam yang diajarkan. Semakin lama siswa belajar semakin bertambah ilmu pengetahuan agamanya. Ilmu pengetahuan adalah alat yang harus dimiliki manusia, jika ia hendak mencapai kesempurnaan dirinya. Disini pun ilmu agama berperan sebagai alat untuk mengantarkan manusia melalui pemahaman dan penggunaan ilmu tersebut untuk meningkatkan ketakwaannya kepada Allah SWT.

2. Nilai formal

Nilai formal adalah nilai pembentukan yang bersangkut dengan daya serap siswa atas segala bahan yang telah diterimahnya. Hal itu berarti sejauh manakah daya serap siswa sehingga ia mampu dengan tenaganya sendiri membentuk kepribadian yang utuh, kokoh dan tahan uji. Semuanya itu merupakan kerja mental sebagai reaksi atas pengaruh yang diterimahnya dan melalui pengalaman kejiwaan terjadi pembentukan berbagai daya rohani yang menjadi ciri kepribadian seseorang.

3. Nilai fungsional

Yang dimaksud dengan fungsional adalah relevansi bahan dengan kehidupan sehari-hari. Jika bahan itu mengandung kegunaan dapat dipakai atau berfungsi dalam kehidupan anak sehari-hari, maka itu berarti mempunyai nilai fungsional. Ditinjau dati segi tuntutan agama, jelas bahwa ajaran itu harus dilaksanakan atau dipakai dalam kehidupan sehari-hari, kalau tidak maka ajaran itu akan kehilangan maknanya. Hak itu berarti bahwa seluruh jumlah bahan dikehendaki terserap dan terpakai dalam segala bentuk dan tingkat kehidupan. ${ }^{17}$

Kenyataan bahwa Pendidikan Agama Islam bernilai fungsional tempat pada:
a) Kehidupan pribadi anak
b) Kehidupan keluarga
c) Kehidupan masyarakat

4. Nilai esensial

Yang dimaksud dengan nilai esensial adalah nilai hakiki. Agama mengajarkan bahwa kehidupan yang hakiki atau hidup yang sebenar-benar hidup itu berlangsung di alam baqa. Jadi kehidupan itu tidak berhenti hingga

${ }^{17}$ Zakiah Daradjat, Metodik Khusus ..., hlm. 192-194. 


\section{Maisaroh}

di dunia saja, melainkan kehidupan itu berlangsung terus dalam akhirat. Ketiga nilai yang telah diutarakan di atas mengandung nilai-nilai ajaran bagi manusia dalam menempuh seluruh kehidupan yang berisi dua, yaitu: dunia dan akhirat.

Dengan demikian seluruh nilai-nilai pengajaran agama Islam bermuara pada nilai hakiki atau nilai esensial, yang berbentuk:

a) Nilai pembersihan atau pensucian rohani/jiwa yang menungkinkan seseorang siap untuk menerima, memahami dan menghayati ajaran agama Islam sebagai pandangan hidupnya.

b) Nilai kesempurnaan akhlak, yang memungkinkan seseorang memilih akhlakul karimah yang tercermin pada sifat-sifat Nabi Muhammad SAW dan mengamalkan ajaran agama Islam secara sempurna sepanjang hayatnya.

c) Nilai peningkatan taqwa kepada Allah SWT, sehingga diri seseorang menjadi semakin akrab kepadaNya dan dengan penuh gairah serta ketulusan hati menyongsong kehidupan yang hakiki. ${ }^{18}$

\section{Pendidikan Taman Kanak-kanak}

Taman Kanak-kanak (TK) merupakan salah satu bentuk pendidikan anak usia yang berusia empat sampai enam tahun pada jalur pendidikan formal yang menyelenggarakan pendidikan untuk mempersiapkan anak menuju sekolah dasar. Nama lain dari Taman Kanak-kanak (TK) yaitu Raudatul Atfal (RA).

Usia empat sampai enam tahun adalah usia anak di Taman Kanakkanak (TK)/ Raudatul Atfal (RA) yang merupakan masa peka bagi anak. Anak mulai sensitif untuk menerima berbagai upaya perkembangan seluruh potensinya. Masa peka merupakan masa terjadinya pemantangan fungsifungsi fisik dan psikis yang siap merespon stimulasi yang diberikan oleh lingkungan. ${ }^{19}$

Masa ini merupakan masa untuk meletakkan dasar pertama dalam mengembangkan kemampuan fisik, kognitif, bahasa, sosial-emosional, konsep diri, disiplin, kemandirian, seni moral dan nilai agama. Oleh sebab itu, dibutuhkan kondisi dan stimulasi yang sesuai dengan kebutuhan anak apabila

${ }^{18}$ Zakiah Daradjat, Metodik Khusus ..., hlm. 195-196.

${ }^{19}$ Mursid, Pengembangan Pembelajaran PAUD (Bandung: PT Remaja Rosdakarya, 2015) hlm. 135. 
lingkungan membatasi kesempatan belajar, maka anak tidak akan mampu mencapai potensi yang seharusnya.

Adapun karakteristik perkembangan anak pada usia Taman Kanakkanak (TK) sebagai berikut:

1. Perkembangan fisik

Anak Taman Kanak-kanak (TK) penuh semangat. Mereka mempunyai banyak energi dan ingin menggunakannya dalam aktivitas fisik seperti berlari, mendaki, melompat. Keinginan mereka untuk ikut serta dalam aktivitas fisik membuat masa Taman Kanak-kanak (TK) masa yang tepat untuk melibatkan anak dalam proses pembelajaran.

2. Perkembangan sosial dan emosional

Ada beberapa hal yang dapat dilakukan seorang pendidik untuk meningkatkan perkembangan sosial dan emosi positif murid Taman Kanakkanak (TK), yaitu:

a) Memberi kesempatan bagi anak untuk ikut serta secara fisik dan mental dalam aktivitas yang mencakup pemecahan masalah dan aktivitas sosial dengan orang lain.

b) Mengajari anak dan mencontohkan cara berteman dan menjaga pertemanan.

c) Memberikan contoh respons sosial dan emosi positif. Membacakan cerita dan membahas perasaan seperti marah, bahagia, bersalah dan bangga.

d) Memberikan anak kesempatan untuk menjadi pemimpin dalam proyek dan aktivitas.

e) Memberitahukan kepada anak tentang sikap-sikap yang baik. ${ }^{20}$

\section{Metodologi Penelitian}

Penelitian ini menggunakan metode penelitian kualitatif. Metode penelitian kualitatif adalah prosedur penelitian yang menghasilkan data deskiptif tentang orang melalui tulisan atau kata-kata yang diucapkan dan perilaku yang dapat diamati..21 Adapun yang menjadi unit analisis/subjek penelitian dalam penelitian ini internalisasi nilai-nilai Pendidikan Agama Islam (PAI). Adapun teknik penentuan informan penelitian dalam hal ini dimaksudkan siswa, peneliti menggunakan pertimbangan snowball sampling

20 George S. Marrison, Dasar-dasar Pendidikan ..., hlm. 254.

${ }^{21}$ Salim dan Syahrum, Metodologi Penelitian Kualitatif (Bandung: Citapustaka Media, 2007), hlm. 46. 


\section{Maisaroh}

(berkembang mengikuti informasi atau data yang diperlukan). Sehingga memungkinkan melibatkan pihak lain yang dapat memberikan informasi. ${ }^{22}$

Hal ini dilakukan karena dari jumlah sumber data yang sedikit itu belum mampu memberikan data yang lengkap, maka mencari orang lagi yang dapat digunakan sebagai sumber data. Dengan demikian jumlah sampel sumber data akan semakin besar, seperti bola salju yang berputar-putar, lama-lama menjadi besar. ${ }^{23}$ Dengan demikian, dalam penelitian ini, peneliti melakukan penelitian sampai peneliti mendapat jawaban yang memuaskan.

\section{Hasil Penelitian}

Berdasarkan hasil observasi ditemukan bahwa model pembelajaran di Taman Kanak-kanak (TK) Islam Terpadu Al-Hijrah berbentuk pembelajaran berbasis sentra. Ada empat sentra, yaitu: sentra al-Islam, sentra bahasa, sentra kognitif dan sentra sains. Dalam pembelajaran ini siswa dibagi ke dalam dua kelompok dan masing-masing kelompok berjumlah 30 anak. Setiap hari siswa bergantian berada di sentra tersebut. Misalnya jika pada hari ini siswa kelompok A berada di sentra al-Islam, maka siswa kelompok B berada di sentra bahasa dan kognitif berhubung karena kedua sentra ini digabung. Demikianlah hari berikutnya, jika kemarin siswa kelompok $A$ berada di sentra al-Islam dan kelompok B berada di sentra bahasa dan kognitif, maka pada hari berikutnya siswa kelompok $\mathrm{A}$ berada di sentra bahasa dan kognitif, sementara itu siswa kelompok B berada di sentra al-Islam. ${ }^{24}$

Mengenai internalisasi nilai-nilai Pendidikan Agama Islam (PAl), ada tiga nilai yang diinternalisasikan dalam sentra al-Islam, yaitu:

a. Nilai akidah

Dari hasil observasi ditemukan nilai-nilai Pendidikan Agama Islam (PAI) yang pertama diinternalisasikan dalam sentra al-Islam adalah nilai akidah. Hal ini didukung oleh hasil wawancara penulis dengan Bapak Azam, ia menjelaskan nilai akidah diinternalisasikan untuk menyahuti perkembangan agama dan moral anak dalam rangka mencapai tujuan Kurikulum 2013 pada

\footnotetext{
${ }^{22}$ Burhan Bungin, Metodologi Penelitian Kualittatif: Aktualisasi Metodologis ke Arah Ragam Varian Kontemporer (Jakarta: PT. Raja Grafindo Persada, 2011), hlm. 144.

23 Sugiono, Metode Penelitian Pendidikan : Pendekatan Kuantitatif, Kualitatif, dan R\&D (Bandung: Alfabeta, 2014), hlm. 300.

24 Observasi, di Taman Kanak-Kanak (TK) Islam Terpadu Al-Hijrah Bintuju Kabupaten Tapanuli Selatan, 6 Maret 2017.
} 
aspek Nilai Agama dan Moral (NAM). ${ }^{25}$ Yang mana tujuannya adalah anak dapat mengenal Tuhan dan agama yang dianutnya serta anak dapat mengucapkan ikrar syahadat.26

Ibu Sihol Marito selaku bidang kurikulum sekaligus guru Taman Kanakkanak (TK) Islam Terpadu Al-Hijrah menjelaskan bahwa materi nilai-nilai akidah yang ditanamkan atau diinternalisasikan, terbagi kepada dua, yaitu: Pertama: Materi akidah yang terdapat di dalam buku cerdas al-Islam misalnya dua kalimat syahadat, bersyukur dan berterima kasih, asmaul husna ar rahman, asmaul husna ar rohim, mengucapkan hamdalah dan nama-nama 25 nabi. Kedua, Materi di luar buku al-Islam yang diperoleh dari kebijakan lembaga sendiri yaitu berbentuk nyanyian yang mengandung nilai-nilai akidah seperti ikrar syahadat, tepuk rukun Islam, tepuk rukun Iman dan sepuluh nama malaikat.

b. Nilai ibadah

Nilai kedua yang diinternalisasikan dalam sentra al-Islam adalah nilai ibadah. Setelah anak diperkenalkan dengan Allah SWT, maka anak diperkenalkan dengan perintah-perintah Allah. Nilai ibadah ini perlu ditanamkan dalam jiwa anak sejak dini agar anak terbiasa untuk beribadah mulai kecil sampai usia tuanya.

Berdasarkan hasil observasi, diketahui bahwa nilai ibadah yang diinternalisasikan adalah seputar tempat beribadah (masjid), ibadah salat, dan cara berwudu. ${ }^{27} \mathrm{Hal}$ ini didukung dengan pernyataan Ibu Nurmayanti bahwa nilai ibadah diberikan kepada anak untuk menyahuti perkembangan agama dan moral anak seperti yang terdapat di Kurikulum 2013 seputar Nilai Agama dan Moral (NAM) yang berisi: Anak dapat menirukan gerakan ibadah sampai pada taraf anak dapat membiasakan diri untuk beribadah. ${ }^{28}$

25 Azam Marpaung, PenyelenggaraTaman Kanak-kanak (TK) Islam Terpadu Al-Hijrah Bintuju Kabupaten Tapanuli Selatan, Wawancara di Kantor Penyelenggara Taman Kanak-Kanak (TK) Islam Terpadu Al-Hijrah Bintuju Kabupaten Tapanuli Selatan, Tanggal 6 Maret 2017.

${ }^{26}$ Kementerian Agama dan Kebudayaan Direktorat Jenderal Pendidikan Anak Usia Dini dan Pendidikan Masyarakat, Kerangka Dasar dan Struktur Kurikulum 2013 Pendidikan Anak Usia Dini (Jakarta: Direktorat Pembinaan Anak Usia Dini, 2015), hlm. 30.

${ }^{27}$ Observasi, di Taman Kanak-Kanak (TK) Islam Terpadu Al-Hijrah Bintuju Kabupaten Tapanuli Selatan, 10 Maret 2017.

${ }^{28}$ Nurmayanti Siregar, Guru Taman Kanak-kanak (TK) Islam Terpadu Al-Hijrah Bintuju Kabupaten Tapanuli Selatan, Wawancara di Kantor Penyelenggara Taman 


\section{Maisaroh}

c. Nilai akhlak

Nilai akhlak juga tidak kalah pentingnya diberikan kepada anak Taman Kanak-kanak (TK) agar mereka dapat berperilaku baik/sopan sejak dini. Demikianlah pendapat Bapak Azam selaku penyelenggara Taman Kanakkanak (TK) Islam Terpadu Al-Hijrah Bintuju Kabupaten Tapanuli Selatan. Lebih lanjut ia mengatakan bahwa nilai akhlak diberikan agar anak dapat berkata dan berperilaku baik disetiap keadaan. Hal ini juga dilakukan dalam rangka optimalisasi perkembangan agama dan moral anak seperti yang terdapat dalam Kurikulum 2013. ${ }^{29}$ Adapun rincian tujuan internalisasi nilai akhlak adalah: Anak dapat mengenal perilaku baik/sopan dan buruk. Anak dapat membiasakan diri berperilaku baik. Anak dapat mengucap salam dan membalas salam. Anak dapat mengucapkan doa sebelum dan sesudah melakukan sesuatu. ${ }^{30}$

\section{Penutup}

Nilai akidah yang diinternalisasikan dalam sentra bahasa adalah materi yang bernilai akidah yang terdapat dalam buku bacaan sederhana dan buku cerita sederhana yang di dalamnya terdapat nilai akidah, ikrar syahadat, tepuk rukun Islam dan rukun Iman. Adapun langkah-langkahnya ada tiga yaitu: Tahap menulis, tahap membaca dan tahap menjelaskan. Pendekatan yang digunakan melalui nyanyian. Metode yang digunakan adalah: Metode menulis, membaca, pembiasaan, ceramah dan cerita.

Nilai ibadah yang diinternalisasikan dalam sentra bahasa adalah tulisan yang mengandung nilai ibadah baik dalam buku bacaan maupun kebijakan guru serta doa/bacaan salat. Langkah-langkah dalam menginternalisasikan nilai ibadah dalam sentra bahasa ada tiga: Menulis, membaca dan menjelaskan. Pendekatannya melalui doa dan metode yang digunakan adalah metode membaca, iqra/membaca, ceramah, hapalan dan pembiasaan.

Kanak-kanak (TK) Islam Terpadu Al-Hijrah Bintuju Kabupaten Tapanuli Selatan, Tanggal 10 Maret 2017.

${ }^{29}$ Azam Marpaung, Penyelenggara Taman Kanak-kanak (TK) Islam Terpadu Al-Hijrah Bintuju Kabupaten Tapanuli Selatan, Wawancara di KantorPenyelenggara Taman Kanak-Kanak (TK) Islam Terpadu Al-Hijrah Bintuju Kabupaten Tapanuli Selatan, Tanggal 15 Maret 2017.

${ }^{30}$ Kementerian Agama dan Kebudayaan Direktorat Jenderal Pendidikan Anak Usia Dini dan Pendidikan Masyarakat, Kerangka Dasar dan Struktur Kurikulum 2013 ..., hlm. 30. 
Nilai akhlak materinya adalah doa sebelum belajar, mengucap salam ketika datang ke sekolah dan pulang sekolah, bersalaman dengan ustazah, janji pulang sekolah, tepuk anak saleh, buku bacaan yang mengandung nilai akhlak dan buku cerita sederhana yang mengandung nilai akhlak. Langkahlangkahnya ada tiga, yaitu: Menulis, Membaca dan menjelaskan. Pendekatannya adalah doa dan nyanyian. Metode yang digunakan adalah metode menulis, iqra (membaca), ceramah, pembiasaan, keteladanan, pengawasan dan nasehat.

\section{Daftar Pustaka}

Asfiati, Manajemen Pembelajaran Pendidikan Agama Islam, Bandung: Citapustaka Media, 2014.

Ali Mudlofir, Aplikasi Pengembangan Kurikulum Tingkat Satuan Pendidikan dan Bahan Ajar Dalam Pendidikan Agama Islam, Jakarta: Rajawali Pres, 2012.

Ahmad Susanto, Perkembangan Anak Usia Dini, Jakarta: Kencana 2012.

Ahmad Nizar, Metode Penelitian Pendidikan, Bandung: Citapustaka Media, 2015.

Abu Ahmadi dan Moor Salimi, Dasar-dasar Pendidikan Agama Islam, Jakarta: Bumi Aksara, 1991.

Abdul Majid, Pembelajaran Tematik Terpadu, Bandung: PT. Rosdakarya, 2014.

Al-Rasyidin, Pendidikan dan Psikologi Islami, Bandung: Cita Pustaka Media, 2007.

Beverly Otto, Perkembangan Bahasa Pada Anak Usia Dini, Diterjemahkan dari "Language Development In Early Childhood" Oleh Tim Penerjemah Prenadamedia Group, Jakarta: Prenadamedia Group, 2015.

Burhan Bungin, Metodologi Penelitian Kualittatif: Aktualisasi Metodologis ke Arah Ragam Varian Kontemporer, Jakarta: PT. Raja Grafindo Persada, 2011.

-----------, Analisis Data Penelitian Kualitatif, Jakarta: Raja Grafindo Persada, 2003.

Deden Makbuloh, Pendidikan Agama Islam, Jakarta: PT RajaGrafondo Persada, 2013.

Depdiknas RI, Undang-undang No. 20 Tahun 2003 Tentang Sistem Pendidikan Nasional, Jakarta : Depdiknas, 2003.

Dessy Anwar, Kamus Besar Bahasa Indonesia, Surabaya: Amelia, 2005. 


\section{Maisaroh}

Pusat Bahasa Departemen Pendidikan Nasional, Kamus Besar Bahasa Indonesia: Edisi Ketiga:, Balai Pustaka, 2005.

E. Mulyasa, Manajemen PAUD, Bandung: PT Rosdakarya, 2014. 2012.

Eveline dan Hartini Nara, Teori Belajar dan Pembelajaran, Bogor: Ghalia Indonesia, 2010.

Eneng Muslihah, I/mu Pendidikan Islam, Jakarta: Diadit Media, 2011.

George S. Marrison, Dasar-dasar Pendidikan Anak Usia Dini, Diterjemahkan oleh Suci Ramadhan dan Apri Widiastuti, Jakarta: PT. Indeks, 2012.

Isjoni, Model Pembelajaran Anak Usia Dini, Bandung: Alfabeta, 2011.

Joko Subagyo, Metode Penelitian dalam Teori dan Praktek, Jakarta: Rineka Cipta, 2004.

Khoiron Rosyadi, Pendidikan Profetik, Yogyakarta: Pustaka Pelajar, 2004.

Kementerian Agama dan Kebudayaan Direktorat Jenderal Pendidikan Anak Usia Dini dan Pendidikan Masyarakat, Kerangka Dasar dan Struktur Kurikulum 2013 Pendidikan Anak Usia Dini, Jakarta: Direktorat Pembinaan Anak Usia Dini, 2015.

Lexy J. Moleong, Metodologi Penelitian Kualitatif, Bandung: PT. Remaja Rosdakarya, 2000.

Mursid, Belajar dan Pembelajaran PAUD, Bandung: PT Remaja Rosdakarya, 2015.

-------, Pengembangan Pembelajaran PAUD, Bandung: PT Remaja Rosdakarya, 2015.

Mukhtar Latif, dkk, Pendidikan Anak Usia Dini, Jakarta: Kencana, 2013.

Miftahul Achyar Kertamuda, Golden Age, Jakarta: Gramedia, 2015.

Muhaimin, Pengembangan Kurikulum Pendidikan Agama Islam, Jakarta: PT. RajaGrafindo Persada, 2010.

------------, Paradigma Pendidikan Islam, Bandung: PT. Remaja Rosdakarya, 2002.

Mohammad Daud Ali, Pendidikan Agama Islam, Jakarta: Raja Grafindo Persada, 2011.

Moeslichatoen, Metode Pengajaran Di Taman Kanak-Kanak, Jakarta: PT Rineka Cipta, 2004. 
Muhammad Najib, Manajemen Strategik Pendidikan Karakter Bagi Anak Usia Dini, Yogyakarta: Gava Media, 2016.

Nurul Zuriah, Metodologi Penelitian Sosial dan Pendidikan, Jakarta: Bumi Aksara, 2006.

Nurgayah, Strategi dan Metode Pembelajaran, Medan: Citapustaka Media Perintis, 2011.

Peraturan Pemerintah Nomor 27 Tahun 1990 tentang Pendidikan Prasekolah.

Rita Mariyana, dkk, Pengelolaan Lingkungan Belajar, Jakarta: Kencana, 2010.

Sudarwan Danim, Perkembangan Peserta Didik, Bandung: Alfabeta, 2013.

Setiadi Susilo, Pedoman Penyelenggaraan PAUD, Jakarta: Media Pustaka, 2016.

Salim dan Syahrum, Metodologi Penelitian Kualitatif, Bandung: Citapustaka Media, 2007.

Suharsimi Arikunto, Prosedur Penelitian: Suatu Pendekatan Praktik, Jakarta: Rineka Ciipta, 2006.

Suyadi, Manajemen PAUD: TPA-KB-TK/RA, Yogyakarta: Pustaka Pelajar, 2011.

Sugiono, Metode Penelitian Pendidikan : Pendekatan Kuantitatif, Kualitatif, dan R\&D, Bandung: Alfabeta, 2014.

Triyo Supriyatno, 'Model Internalisasi Nilai-nilai Keagamaan di Ma'had Sunan Ampel Al-Ali UIN Malang", dalam el-Qudwah Jurnal Penelitian \& Pengembangan, Volume: I, nomor I, April, 2006, hlm. 86-87.

Zakiah Daradjat, Metodik Khusus Pengajaran Agama Islam, Jakarta: Bumi Aksara, 2014. 